\title{
Larvicidal and Adult Mosquito Vector Attractant Activity of Tremella fuciformis Berk Mushroom Extract on Aedes aegypti (L.) and Culex sitiens Wiedemann (Diptera: Culicidae)
}

\author{
Tanawat Chaiphongpachara ${ }^{1 *}$, Kantima Sumchung ${ }^{2}$, Aegkapun Bumrungsuk ${ }^{2}$, Kitthisak Khlaeo Chansukh ${ }^{3}$ \\ ${ }^{1}$ College of Allied Health Sciences, Suan Sunandha Rajabhat University, Thailand. \\ ${ }^{2}$ Bachelor of Public Health, College of Allied Health Sciences, Suan Sunandha Rajabhat University, Thailand. \\ ${ }^{3}$ Department of Applied Thai Traditional Medicine, College of Allied Health Sciences, Suan Sunandha Rajabhat University, Thailand.
}

\begin{tabular}{l}
\hline ARTICLE INFO \\
\hline Article history: \\
Received on: 09/06/2018 \\
Accepted on: 19/07/2018 \\
Available online: 30/09/2018 \\
\hline Key words: \\
Tremella fuciformis \\
mushroom, Aedes aegypti, \\
Culex sitiens, larvicidal \\
effect, mosquito attractant \\
effect.
\end{tabular}

\section{INTRODUCTION}

Mosquito-borne diseases are a major public health issue, especially in tropical and subtropical countries. They include Zika virus disease, malaria, dengue fever, Japanese encephalitis, chikungunya, and filariasis (Service, 2008; World Health Organization, 2016). Globally, more than 1 million people die from these diseases every year (World Health Organization, 2014). In Thailand, mosquito-borne diseases are one of the most important health concerns, requiring urgent resolution. According to Ministry of Public Health of Thailand reports, in 2016 dengue fever had the highest incidence rate at 58.79 cases per one hundred thousand people, followed by malaria, chikungunya, Japanese encephalitis, and filariasis (Ministry of Public Health, 2016). For

\footnotetext{
${ }^{*}$ Corresponding Author

Tanawat Chaiphongpachara, College of Allied Health Science, Suan Sunandha Rajabhat University, Samut Songkhram 75000, Thailand. E-mail:tanawat.ch@ssru.ac.th
}

control of mosquito borne diseases to reduce the risk of infection will focus mosquito population in the endemic area (Roiz et al., 2012) in two ways including reducing the number of both the larval and adult stages of mosquitoes.

Currently, the most common and popular method for controlling mosquitoes is the use of chemical insecticides, but these have harmful effects on humans, animals, and the environment (Nkya et al., 2013). Furthermore, mosquitoes have become resistant to some insecticides, for example, the larvicide temephos (Chaiphongpachara et al., 2017). Thailand has reported mosquito resistance in many areas, resulting in difficulties in controlling the dengue vector population (Pimsamarn et al., 2009).

Mosquito traps are useful tools to reduce mosquito populations (Okumu et al., 2010). Currently, various odors are used for trap optimization, including octenol, carbon dioxide, and lactic acid. These are based on the olfactory attraction of female mosquitoes, which require proteins from the blood of humans or animals for egg production (Takken and Kline, 1989). 
Octenol (1-octen-3-ol) is a volatile organic compound found in the perspiration and breath of humans or animals. It has also been reported that octenol is found in some mushrooms and that it is toxic to insects (Inamdar and Bennett, 2014). Recently, studies have reported that some mushrooms have larvicidal activity including Aspergillus flavus, Chrysosporium lobatum, Penicillium spp., Podospora spp., Xylaria nigripes, Chlorophyllum spp., Steccherinum spp. and Thaeogyroporus porentosus (Matasyoh et al., 2011; Mohanty and Prakash, 2009; Govindarajan et al., 2005; Thongwat et al., 2015). It is possible, therefore, that certain fungi could have both adult attractant and larvicidal properties, with potential as an alternative method of mosquito control.

We selected Tremella fuciformis Berk, an edible fungus that is popular with consumers in Thailand, for assay of larvicidal and adult mosquito attractant activity, and we tested this on Aedes aegypti (L.) (a dengue fever vector) and Culex sitiens Wiedemann (a filariasis and Japanese encephalitis vector), both major vectors in coastal habitats (Chaiphongpachara and Sumruayphol, 2017).

\section{MATERIALS AND METHODS}

\section{Mushroom collection and extract preparation}

T. fuciformis mushrooms were purchased during September 2016 from Talat Thai market, Pathum Thani province in Thailand $\left(14^{\circ} 4^{\prime} 54.51^{\prime \prime} \mathrm{N}, 100^{\circ} 37^{\prime} 53.06^{\prime \prime} \mathrm{E}\right)$, and then taken to the College of Allied Health Sciences, Suan Sunandha University, Samut Songkhram province education center. They were then washed thoroughly and their identity confirmed by morphological characteristics using taxonomic identification keys (Largent and Thiers, 1977).

The mushrooms were dried in the shade at ambient temperature $\left(\sim 37^{\circ} \mathrm{C}\right)$, ground into powder using a blender, and infused in $95 \%$ ethanol at room temperature for 48 hours. The mushroom extract was filtrated through Whatman filter paper and dried in a rotary evaporator. The yield of crude extract was recorded, dissolved in methanol for adult mosquito bioassay and distilled water for larvicidal bioassay, and stored at $-20^{\circ} \mathrm{C}$ before investigations in the laboratory.

\section{Mosquito collection and rearing}

Eggs of Ae. aegypti (WHO susceptible strain BoraBora) were supplied by the Faculty of Tropical Medicine, Mahidol University, while $C x$. sitiens larvae, a coastal vector, and were collected using a standard mosquito dipper from water with a salinity level of more than $0.05 \mathrm{ppt}$ in coastal areas of Samut Songkhram province, Thailand, $200 \mathrm{~m}$ inland from the sea. The eggs and larvae were placed separately in trays $(25 \times 30 \times 5 \mathrm{~cm})$ containing filtered water and rearing were carried out at $25 \pm 2{ }^{\circ} \mathrm{C}$ with 10:14 h light: dark cycle with $0.1 \mathrm{~g}$ food provided daily. The pupae were transferred to cages $(30 \times 30 \times 30 \mathrm{~cm})$ for adult mosquito emergence.

\section{Larvicidal bioassay}

Larvicidal bioassay of the T. fuciformis extract was conducted following WHO protocols (WHO, 2016). Five concentrations of mushroom extract were prepared $(120,12,1.2$, 0.12 , and $0.012 \mathrm{mg} / \mathrm{L}$ ) using filtered water in six-ounce glass containers, to which were added 20 late third instar or early fourth instar larvae. After $24 \mathrm{~h}$ the number of dead larvae was counted and recorded. All experiments were done in triplicate. For the control group, we used a mixture of filtered water and extraction solvent. Octenol (1-Octanol EMPLURA ${ }^{\circledR}$ from Merck KGaA COMPANY, Darmstadt, Germany) at the same concentrations was used as a benchmark for testing against larvae and ault mosquitoes.

\section{Adult mosquitoes attractant bioassay}

Mushroom extract at concentrations of 100,10 , and 1 $\mathrm{mg} / \mathrm{L}$ following Cilek et al. (2011) were used in adult mosquito attraction tests, conducted using a modified Y-tube, according to the method of Geier et al. (Geier and Boeckh, 1999). At each concentration level, 20 healthy adult female mosquitoes were tested, with four replicates at each concentration. In this bioassay, one arm of the Y-tube provides a flow of the test substance (the T. fuciformis extract) and the other is the control; when all 20 mosquitoes had flown down either one arm or the other, we counted and recorded the results.

\section{Statistical analyses}

Numbers of dead larvae and numbers of mosquito attracted were expressed as mean \pm S.D. (standard deviation). The T-test was used for comparisons, with differences regarded as significant at $p \leq 0.05$.

\section{RESULTS AND DISCUSSION}

\section{Efficacy of $T$. fuciformis extract as a larvicide}

At all concentrations, T. fuciformis extract showed no larvicidal activity against Ae. aegypti, and only a slight (nonsignificant) effect against $C x$. sitiens. (Table 1), while Octenol at the highest concentration $(120 \mathrm{mg} / \mathrm{L})$ killed nearly all the $C x$ sitiens larvae $(19.00 \pm 1.00$ of 20$)$ and around half the Ae. aegypti larvae $(9.00 \pm 1.00$ of 20$)$. In the control groups, none of the Ae. aegypti larvae died, and only very few of the $C x$. sitiens larvae died.

\section{Efficacy of $T$. fuciformis extract for attracting adult mosquitoes}

At all concentrations, octenol was a significantly $(p \leq 0.05)$ better attractant for Ae. aegypti and Cx. sitiens than T. fuciformis extract (Table 2). Of the three concentrations of attractants tested, the intermediate concentration $(10 \mathrm{mg} / \mathrm{L})$ was most effective for both species, followed by 100 and $1 \mathrm{mg} / \mathrm{L}$. Ae. aegypti adults were more attracted than $C x$. sitiens in all tests.

We studied the larvicidal effect and adult female mosquito attractant activity of T. fuciformis mushroom extract on Ae. aegypti and $C x$. sitiens. There are reports of the toxicity of octenol to small insects (Inamdar and Bennett, 2014) consistent with the results of this study; here, the highest concentration (120 $\mathrm{mg} / \mathrm{L})$ killed almost all $C x$. sitiens larvae $(19.00 \pm 1.00$ of 20$)$ and about half the Ae. aegypti larvae $(9.00 \pm 1.00$ of 20). However, the T. fuciformis mushroom extract was not effective against Ae. aegypti larvae and only very slightly effective on $C x$. sitiens larvae and our results indicate that it is unlikely that $T$. fuciformis extracts as prepared in this study could be used to control mosquito larvae. This result is consistent with that of Thongwat et al. (2015), who screened 143 species of mushroom against Ae. aegypti larvae in the laboratory and found larvicidal activity in only Thaeogyroporus porentosus, Xylaria nigripes, Chlorophyllum spp., Steccherinum spp., and two unidentified species. 
Table 1: Mean number of dead larvae of Ae. aegypti and Cx. sitiens.

\begin{tabular}{|c|c|c|c|c|c|}
\hline \multirow{3}{*}{ Concentrations, $(\mathrm{mg} / \mathrm{L})$} & \multirow{3}{*}{$\mathbf{n}$} & \multicolumn{4}{|c|}{ Number of dead mosquito larvae } \\
\hline & & \multicolumn{2}{|c|}{ Ae. aegypti } & \multicolumn{2}{|c|}{ Cx. sitiens } \\
\hline & & $\begin{array}{l}\text { T. fuciformis extract } \\
\text { Mean } \pm \text { S.D. }\end{array}$ & $\begin{array}{c}\text { Octenol } \\
\text { Mean } \pm \text { S.D. }\end{array}$ & $\begin{array}{l}\text { T. fuciformis extract } \\
\text { Mean } \pm \text { S.D. }\end{array}$ & $\begin{array}{c}\text { Octenol } \\
\text { Mean } \pm \text { S.D. }\end{array}$ \\
\hline 120 & 20 & $\mathrm{ND}^{\mathrm{a}}$ & $9.00 \pm 1.00^{\mathrm{b}}$ & $1.00 \pm 0.00^{\mathrm{a}}$ & $19.00 \pm 1.00^{b}$ \\
\hline 12 & 20 & $\mathrm{ND}^{\mathrm{a}}$ & $0.33 \pm 0.58^{\mathrm{b}}$ & $1.00 \pm 1.00 \mathrm{a}$ & $9.33 \pm 0.33^{b}$ \\
\hline 1.2 & 20 & $\mathrm{ND}^{\mathrm{a}}$ & $0.33 \pm 0.58^{\mathrm{b}}$ & $0.67 \pm 0.58^{\mathrm{a}}$ & $6.00 \pm 1.00^{\mathrm{b}}$ \\
\hline 0.12 & 20 & $\mathrm{ND}^{\mathrm{a}}$ & $1.00 \pm 1.00^{\mathrm{b}}$ & $0.67 \pm 0.58^{\mathrm{a}}$ & $5.00 \pm 2.65^{\mathrm{b}}$ \\
\hline 0.012 & 20 & $\mathrm{ND}^{\mathrm{a}}$ & $0.33 \pm 0.58^{\mathrm{b}}$ & $1.00 \pm 0.00^{\mathrm{a}}$ & $1.00 \pm 1.00^{\mathrm{a}}$ \\
\hline Control group & 20 & ND & ND & $0.67 \pm 0.58$ & $1.33 \pm 0.33$ \\
\hline
\end{tabular}

$\mathrm{ND}=$ No deaths, and the same letter in the row between T. fuciformis extract and octenol in each concentration is not significantly different at $p \leq 0.05$.

Table 2: Mean number of responding adult Ae. aegypti and $C x$. sitiens.

\begin{tabular}{|c|c|c|c|c|c|}
\hline \multirow{3}{*}{ Concentrations, $(\mathrm{mg} / \mathrm{L})$} & \multirow{3}{*}{$\mathbf{n}$} & \multicolumn{4}{|c|}{ Attracted mosquito } \\
\hline & & \multicolumn{2}{|c|}{ Ae. aegypti } & \multicolumn{2}{|c|}{ Cx. sitiens } \\
\hline & & $\begin{array}{l}\text { T. fuciformis extract } \\
\text { Mean } \pm \text { S.D. }\end{array}$ & $\begin{array}{c}\text { Octenol } \\
\text { Mean } \pm \text { S.D. }\end{array}$ & $\begin{array}{l}\text { T. fuciformis extract } \\
\text { Mean } \pm \text { S.D. }\end{array}$ & $\begin{array}{c}\text { Octenol } \\
\text { Mean } \pm \text { S.D. }\end{array}$ \\
\hline 100 & 20 & $11.33 \pm 0.57^{\mathrm{a}}$ & $15.00 \pm 1.00^{\mathrm{b}}$ & $5.66 \pm 0.57^{\mathrm{a}}$ & $11.33 \pm 0.33^{b}$ \\
\hline 10 & 20 & $13.33 \pm 0.57^{\mathrm{a}}$ & $17.33 \pm 0.57^{\mathrm{b}}$ & $7.00 \pm 0.00^{\mathrm{a}}$ & $12.00 \pm 0.00^{\mathrm{b}}$ \\
\hline 1 & 20 & $12.33 \pm 0.57^{\mathrm{a}}$ & $16.00 \pm 0.00^{\mathrm{b}}$ & $6.66 \pm 0.57^{\mathrm{a}}$ & $11.66 \pm 0.57^{\mathrm{b}}$ \\
\hline
\end{tabular}

The same letter in the row between T. fuciformis extract and octenol in each concentration is not significantly different at $p \leq 0.05$.

Apart from octanol's toxicity to aquatic insects, it is a substance that can be used to attract mosquitoes. Octenol is a powerful attractant for female mosquitoes looking for a blood meal, and several studies have reported that octenol is contained in mushrooms, including T. fuciformis (Mau et al., 1997). The T. fuciformis extract used in our study attracted more than $60 \%$ of Ae. aegypti at a concentration of $10 \mathrm{mg} / \mathrm{L}$, though at the same concentration the rate of attraction for $C x$. sitiens was poorer at around $35 \%$. These results are consistent with previous research that found that octenol at a concentration of $10 \mathrm{mg} / \mathrm{L}$ was best for attracting mosquitoes, with Aedes spp. more attracted than Culex spp. (Cilek et al., 2011). In this study, the T. fuciformis extract produced a significantly lower attraction response than octenol at all concentrations $(p \leq 0.05)$, a difference that may arise from the concentration of bioactive substances in the T. fuciformis mushroom.

\section{CONCLUSION}

This experiment is the first to reveal the ability of $T$. fuciformis mushroom extract to control mosquitoes. Although the performance of T. fuciformis extract is not equal to that of octanol, it was effective in attracting more than half of all mosquitoes in the laboratory tests and could be an eco-friendly way to increase the efficiency of mosquito traps.

\section{ACKNOWLEDGMENTS}

We would like to thank the College of Allied Health Science, Suan Sunandha Rajabhat University, Thailand, for their kind support of our research.

\section{REFERENCES}

Chaiphongpachara T, Sumruayphol S. Species diversity and distribution of mosquito vectors in coastal habitats of Samut Songkhram province, Thailand. Trop Biomed. 2017; 34:524-532.

Chaiphongpachara T, Moolrat L. Insecticide resistance of temephos on Aedes aegypti as dengue vector in Samut Songkhram, Thailand. Ann Trop Med Public Health, 2017; 10:1439-1442.

Cilek JE, Ikediobi CO, Hallmon CF, Johnson R, Onyeozili EN, Farah SM, Mazu T, Latinwo LM, Ayuk-Takem L, Berniers UR. Semi-field evaluation of several novel alkenol analogs of 1-octen-3-ol as attractants to adult Aedes albopictus and Culex quinquefasciatus. J Am Mosq Control Assoc, 2011; 27:256-262.

Geier M, Boeckh J. A new Y-tube olfactometer for mosquitoes to measure the attractiveness of host odours. Entomol Exp Appl, 1999; 92:919.

Govindarajan M, Jebanesan A, Reetha D. Larvicidal effect of extracellular secondary metabolites of different fungi against the mosquito, Culex quinquefasciatus Say. Trop Biomed, 2005; 22:1-3.

Inamdar AA, Bennett JW. A common fungal volatile organic compound induces a nitric oxide mediated inflammatory response in Drosophila melanogaster. Sci Rep, 2014; 4.

Largent DL, Thiers HD. 1977. How to identify mushrooms to genus II: field identification of genera. Eureka: Eureka Printing.

Matasyoh JC, Dittrich B, Schueffler A, Laatsch H. Larvicidal activity of metabolites from the endophytic Podospora sp. against the malaria vector Anopheles gambiae. Parasitol Res, 2011; 108:561-566.

Mau JL, Chyau CC, Li J, Tseng YH. Flavor compounds in straw mushrooms Volvariella volvacea harvested at different stages of maturity. J Agric Food Chem, 1997; 45:4726-4729.

Ministry of Public Health, Thailand. 2016. http://www.thaivbd. org/n/home; Accessed 15 Dec 2017.

Mohanty SS, Prakash S. Effects of culture media on larvicidal property of secondary metabolites of mosquito pathogenic fungus Chrysosporium lobatum (Moniliales: Moniliaceae). Acta Trop, 2009; 109:50-54.

Nkya TE, Akhouayri I, Kisinza W, David JP. Impact of environment on mosquito response to pyrethroid insecticides: Facts, evidences and prospects. Insect Biochem Mol Biol, 2013; 43:407-416. 
Okumu FO, Madumla EP, John AN, Lwetoijera DW, Sumaye RD. Attracting, trapping and killing disease-transmitting mosquitoes using odor-baited stations - The Ifakara Odor-Baited Stations. Parasites and Vectors, 2010; 3 .

Pimsamarn S, Sornpeng W, Akksilp S, Paeporn P, Limpawitthayakul M. Detection of insecticide resistance in Aedes aegypti to organophosphate and synthetic pyrethroid compounds in the north-east of Thailand. Dengue Bull, 2009; 33:194-202.

Roiz D, Roussel M, Munõz J, Ruiz S, Soriguer R, Figuerola, J. Efficacy of mosquito traps for collecting potential west nile mosquito vectors in a natural mediterranean wetland. Am J Trop Med Hyg, 2012; $86: 642-648$

Service M. 2008. Medical entomology for students, fourth edition, Medical Entomology for Students, Fourth Edition.

Takken W, Kline DL. Carbon dioxide and 1-octen-3-ol as mosquito attractants. J Am Mosq Control Assoc, 1989; 5:311-316.

Thongwat D, Pimolsri U, Somboon P. Screening for mosquito larvicidal activity of thai mushroom extracts with special reference to
Steccherinum sp against Aedes aegypti (L.) (Diptera: Culicidae). Southeast Asian J Trop Med Public Health, 2015; 46:586-595.

World Health Organization, Monitoring and managing insecticide resistance in Aedes mosquito populations Interim guidance for entomologists. WHO. 2016

World Health Organization, Mosquito born diseases. WHO.

2016.

World Health Organization, WHO Factsheet Vector-borne diseases. Factsheet number 387. 2014; 10.

How to cite this article:

Chaiphongpachara T, Sumchung K, Bumrungsuk A, Chansukh KK. Larvicidal and Adult Mosquito Vector Attractant Activity of Tremella fuciformis Berk Mushroom Extract on Aedes aegypti (L.) and Culex sitiens Wiedemann (Diptera: Culicidae). J App Pharm Sci, 2018; 8(09): 007-010. 